\title{
THE IMPROVEMENT OF BETULIN-3, 28-DIPHOSPHATE WATER-SOLUBILITY BY COMPLEXATION WITH AMINES-MEGLUMINE AND XYMEDON
}

\author{
NINA MELNIKOVA ${ }^{a^{*}}$, DARINA MALYGINA ${ }^{a}$, DMITRY PANTELEEV ${ }^{a}$, OLGA VOROBYOVA $^{a}$, ANNA SOLOVYEVA ${ }^{b}$, \\ KSENIYA BELYAEVA ${ }^{b}$, IRINA KLABUKOVA ${ }^{a}$
}

\begin{abstract}
${ }^{a}$ Department of Pharmaceutical Chemistry, Federal State Budgetary Educational Institution of Higher Education "Privolzhsky Research Medical University", Ministry of Health of the Russian Federation, Minin sq., 10/1, 603005 Nizhny Novgorod, Russia, bLaboratory of Experimental Medicine, Federal State Budgetary Educational Institution of Higher Education "Privolzhsky Research Medical University", Ministry of Health of the Russian Federation, Minin sq., 10/1, 603005 Nizhny Novgorod, Russia
\end{abstract} Email: melnikovanb@gmail.com

Received: 20 Feb 2017 Revised and Accepted: 06 Apr 2019

\section{ABSTRACT}

Objective: To study betulin-3,28-diphosphate (BDP) water solubility improved by forming salt complexes with hydrophilic amino alcohols: meglumine as acidosis corrector and xymedon as the water-soluble antioxidant.

Methods: We used ${ }^{13} \mathrm{C}-$, ${ }^{31} \mathrm{P}-\mathrm{NMR}$, UV-spectroscopy and potentiometric titration to study the BDP-amine salt complexes formation and their solubility using HPLC-analysis.

Results: The participation of xymedon in the proton transfer reaction with BDP in aqueous solutions was confirmed by the bathochromic shift of the carbonyl band from $299.1 \mathrm{~nm}$ to $304.2 \mathrm{~nm}$, and by a hyperchromic effect (molar extinction $\varepsilon$ from 8508 to $10441 \mathrm{l} \cdot \mathrm{mol}^{-1} \cdot \mathrm{cm}^{-1}$ ) in UV-spectra. BDP complexation with meglumine was estimated by UV-spectral molar ratio method at $256 \mathrm{~nm}$. Molar ratio of BDP-amine complexes (1:4) was proved by ${ }^{31} \mathrm{P}-\mathrm{NMR}$. The chemical shift of phosphorus at $\mathrm{C}-3$ atom of BDP $(\delta=-0.58 \mathrm{ppm})$ changed to $+3.39 \mathrm{ppm}$, and at $\mathrm{C}-28 \mathrm{atom}(\delta=+0.28 \mathrm{ppm})-$ to $+4.60 \mathrm{ppm}$. BDP solubility increased 100-600 fold according to HPLC-analysis.

Conclusion: BDP interaction with amine in an aqueous solution was shown to proceed via a proton transfer due to relatively weak forces such as London forces, hydrogen bonding, electrostatic and hydrophobic interactions. In general, the formation of BDP salt complexes with amines in solution determines BDP water solubility. Water-soluble BDP enables to develop hydrophilic dosage forms.

Keywords: Poorly water-soluble, Salt complex engineering, Betulin-3,28-diphosphate, Meglumine, Xymedon

(C) 2019 The Authors. Published by Innovare Academic Sciences Pvt Ltd. This is an open access article under the CC BY license (http://creativecommons.org/licenses/by/4.0/) DOI: http://dx.doi.org/10.22159/ijpps.2019v11i5.32707

\section{INTRODUCTION}

Lupane triterpenoids such as betulin (lup-20(29)-ene-3,28-diol) and its derivatives extracted from renewable natural resources [1-3], e. g. from birch bark, exhibit various types of pharmacological activity. The antioxidant, anti-inflammatory, hepatoprotective, antimutagenic, and other activities of the compounds were demonstrated by in vitro and in vivo experiments [4-9]. Recent studies have shown that betulin can be a useful structural scaffold in drugs to prevent and treat osteoclastmediated bone diseases [8].

The major problem to develop a dosage form, for most types of triterpenes, including betulin derivatives, is their low water-solubility [10]. The methods to increase the triterpenoids solubility are the formation of multiarm-polyethylene glycol-betulinic acid prodrugs [11], betulin diacetate complexes with polysaccharides [12], esters of betulin and betulinic acid with amino acids [13], salt of betulinic acid derivatives with organic cations (didecyldimethylammonium, choline and benzalkonium), alkali metals, etc. $[14,15]$. The suitable techniques to modify and graft additional polar groups are the formation of sulfates, phosphonate and phosphate groups [16-22]. Moreover, the phospholipid derivatives of betulin with improved solubility were synthesized [17]. The betulin sulphates have been demonstrated to be selective potent inhibitors of $\mathrm{C} 1 \mathrm{q}$ interaction of with immunoglobulins and the classical pathway of complement activation [16]. The most favorable modification is the grafting of phosphate derivatives by 3- or $28-\mathrm{OH}$ groups of betulin resulting in solubility improvement in comparison with the extremely low solubility of natural betulin (about $1.0 \cdot 10^{-4}-1.9 \cdot 10^{-3} \mathrm{~g} \cdot \mathrm{l}^{-1}$ depending on conditions) [17-22].

Fig. 1a shows betulin-3,28-diphosphate (BDP) obtained by betulin phosphorylation with phosphorus oxychloride, BDP solubility in water is $50-1000$ times higher than that of betulin, and its sodium salt (Na-BDP) solubility in water is up to $10 \mathrm{~g} \cdot \mathrm{l}^{-1}$ [18].

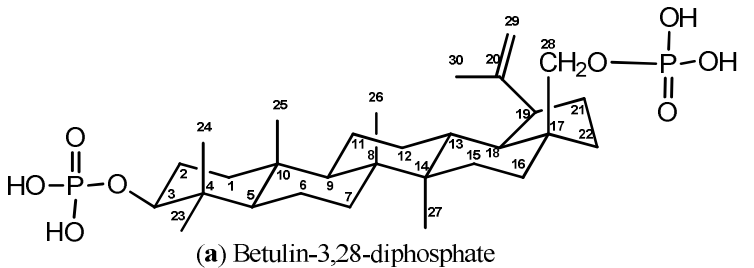<smiles>CNC[C@H](O)[C@@H](O)[C@H](O)[C@H](O)CO</smiles>

(b) Meglumine<smiles>Cc1cc(C)n(CCO)c(=O)n1</smiles>

(c) Xymedon
Fig. 1: Formulas of salt complexes components

In addition to improved solubility, betulin phosphates and phosphonates showed high activity as potential drugs [18-23]. In vitro and in vivo experiments demonstrated antimicrobial [19], antifungal [20], anti-inflammatory, antiviral [21] activities and an antitumor effect in the treatment of ductal carcinoma, glioblastoma, melanoma [22], Ehrlich ascites carcinoma [23] and other diseases.

However, the problem of using both betulin-3, 28-diphosphate and its sodium salts as an active pharmaceutical ingredient is the solubility reduction of these substances in storage. The aging of samples leads to the formation of a different structural modification characterized by more close packing of solid layers. The crystallization water of the hydrate $\mathrm{Na}-\mathrm{BDP} \cdot 8 \mathrm{H}_{2} \mathrm{O}$ was removed 
from molecules with time [18]. In this regard, it is very important to find methods to increase and stabilize BDP solubility. The findings may be useful to design new dosage forms including injectable preparations and hydrophilic gels.

Meglumine ((2R,3R,4R,5S)-6-(methylamino)hexan-1,2,3,4,5-pentol, $\mathrm{Megl})$ traditionally used both for acidosis correction, $\mathrm{pH}$-regulation and making plasma isoosmotic and to improve permeability of poorly soluble lipophilic pharmaceutical substances [24, 25] was chosen as one of these amino alcohols (fig. 1b).

A readily soluble drug having an amino alcohol group, e. g., a pharmaceutical active ingredient-xymedon (fig. 1c), also can be used as a component of a salt complex with BDP. In this case, the BDP molecule exhibiting weak acid properties can act as a component of a drug delivery vector for the group of amines with weak basic properties. Xymedon (1-( $\beta$-hydroxyethyl)-4,6-dimethyl-1,2-dihydro2-hydroxy-pyrimidine, Xym) is a heterocyclic amino alcohol having high antioxidant, reparative, anti-inflammatory and other activities [26]. The abnormal water solubility of xymedon (about $400 \mathrm{~g} \cdot \mathrm{l}^{-1}$ ) and high pharmacological properties suggest that a complex of xymedon with betulin-3,28-diphosphate can be a novel antioxidant drug with an optimal BDP dose.

In this paper, we studied the possibility of improving BDP water solubility by forming BDP water-soluble salt complexes with hydrophilic amino alcohols in solution.

\section{MATERIALS AND METHODS}

\section{Materials}

Betulin was isolated from birch bark (Betula Pendula) using the methods [27]. The materials were meglumine (Merck, TD 13015143333), xymedon (Sigma Aldrich, Moscow, Russia), lithium perchlorate (Sigma Aldrich, Moscow, Russia), phytic acid solution 50 $\%$ (w/w) in $\mathrm{H}_{2} \mathrm{O}$ (Sigma Aldrich, Moscow, Russia), purified water (resistivity $\geq 18 \mathrm{M} \Omega \cdot \mathrm{cm}$, Millipore, Merck, Darmstadt, Germany).

\section{FTIR analysis}

FTIR spectra in $400-4000 \mathrm{~cm}^{-1}$ range were measured by an IR Prestige-21 FTIR spectrometer (Shimadzu, Kyoto, Japan) equipped with a $\mathrm{KBr}$ beam splitter. To perform the measurements, a pellet from a well-dried $\mathrm{KBr}$ was prepared according to standard cold pressing. Resolution was $0.5 \mathrm{~cm}^{-1}$. The number of scans was 45 .

\section{UV analysis}

UV-spectra were recorded by UV-1800 (Shimadzu, Kyoto, Japan).

\section{RP-HPLC analysis}

RP-HPLC-analysis was carried out on LC-20Avp (Shimadzu, Kyoto, Japan) with UV-detection, the column is Discovery C18 (25 cm x 4.6 $\mathrm{mm}, 5 \mu \mathrm{m}$, Supelco), retention time $\tau$ equals to $5.19 \mathrm{~min}$.

\section{NMR analysis}

${ }^{13} \mathrm{C}-,{ }^{1} \mathrm{H}-,{ }^{31} \mathrm{P}-\mathrm{NMR}$ spectra were recorded at 101,400 and 202,46 MHz, respectively, on a JNM-ECX400 NMR-spectrometer (Jeol Ltd., Tokyo, Japan), DMSO- $\mathrm{d}_{6}$ and $\mathrm{D}_{2} \mathrm{O}$ being used as solvents.

\section{Solubility determination}

Solubility was measured by shake-flask method [28]. An excess amount of BDP was added to the buffer solution ( $\mathrm{pH}$ 6.8) by magnetic stirring during $24 \mathrm{~h}$ at $20^{\circ} \mathrm{C}$. The added BDP amount was enough to make a saturated solution in equilibrium with solid phase. After phase separation of saturated solution by filtration a liquid phase was analysed by RP-HPLC in isocratic modes $\left(210 \mathrm{~nm}, 40^{\circ} \mathrm{C}\right.$, mobile phase A30\%-B70\% v/v, A-acetonitrile, grade 0, B-buffer solution of $\mathrm{KH}_{2} \mathrm{PO}_{4}, \mathrm{pH}=6.36$; sample volume is equal to $20 \mu \mathrm{L}$, flow $1.0 \mathrm{ml} \cdot \mathrm{min}^{-1}$. The retention time is $5.19 \mathrm{~min}$.).

\section{Synthesis of betulin-3, 28-diphosphate and its sodium salt}

Betulin-3, 28-diphosphate (BDP, 33, 28-diphosphate-lup-20(29)-ene) and its sodium salt were synthesized according to the procedure [18]. ${ }^{13} \mathrm{C}-{ }^{-31} \mathrm{P}$ and ${ }^{1} \mathrm{H}-\mathrm{NMR}$ spectra and physicochemical constants were in accordance with literature data [18]. BDP and its sodium salt assay were performed by reversed phase HPLC analysis: $210 \mathrm{~nm}, 40{ }^{\circ} \mathrm{C}$, mobile phase $\mathrm{A} 30 \%-\mathrm{B} 70 \% \mathrm{v} / \mathrm{v}(\mathrm{A}$-acetonitrile (grade 0), B-buffer solution of $\mathrm{KH}_{2} \mathrm{PO}_{4}, \mathrm{pH}=6.36$ ), flow $1.0 \mathrm{ml} \cdot \mathrm{min}^{-1}$. The retention time of BDP and its sodium salt was $5.19 \mathrm{~min}$ and $4.51 \mathrm{~min}$, correspondingly.

\section{Biological activity in vitro}

Biological activity in vitro was studied using blood stabilized with sodium citrate (1:9).

Catalase activity (EC 1.11.1.6) was determined by spectrophotometry based on hydrogen peroxide decomposition by the catalase [29]. Glutathione reductase activity (EC 1.8.1.7) was studied spectrophotometrically based on oxidized glutathione reduction [30]. The activity of glucose-6-phosphate dehydrogenase (EC 1.1.1.49) was determined in hemolysate of erythrocytes using spectrophotometry based on glucose-6-phosphate oxidation to the phosphoglucolactone with the formation of reduced nicotinamide adenine dinucleotide phosphate (NADPH) [31].

The study as presented was approved by the Local Ethics Committee of Privolzhsky Research Medical University, Russian Federation (Protocol No.2-20.02.16 dated 20 February 2016).

\section{RESULTS}

Acid-base interactions of betulin-3, 28-diphosphate with aqueous solutions of amines (xymedon and meglumine)

The $\mathrm{pH}$ decreased from the initial values $\mathrm{pH}{ }^{0} \mathrm{Megl}$ and $\mathrm{pH}{ }^{0} \mathrm{xym}$ to $\mathrm{pH}$ 3.75 in the potentiometric titration of $5.9 \cdot 10^{-5} \mathrm{M}$ xymedon (Xym) and meglumine (Megl) aqueous solutions by $2.9 \cdot 10^{-3} \mathrm{M}$ BDP ethanol solution (fig. 2).

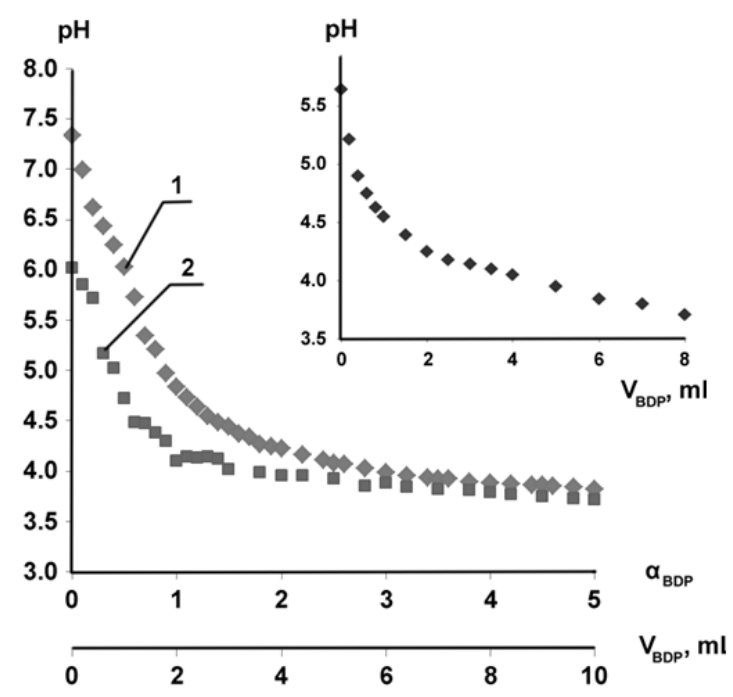

Fig. 2: The pH dependence on molar fraction $\alpha, \mathrm{pH}=\mathrm{f}\left(\alpha_{\mathrm{BDP}}\right) ; \alpha=$ $\mathbf{n}_{\mathrm{BDP}} / \mathbf{n}_{\text {amine. }}$ The titration of $5.9 \cdot 10^{-5} \mathrm{M}$ amine aqueous solution by $2.9 \cdot 10^{-3} \mathrm{M}$ BDP ethanol solution: 1-meglumine; 2-xymedon. The inset shows $\mathrm{pH}=\mathrm{f}\left(\mathrm{V}_{\mathrm{BDP}}\right)$ after adding $2.9 \cdot 10^{-3} \mathrm{M}$ BDP ethanol solution to water in a blank experiment. The initial amine solution volume was $100 \mathrm{ml}$

The $\mathrm{pH}=\mathrm{f}\left(\alpha_{\mathrm{BDP}}\right)$ curves, where molar fraction $\alpha=\mathrm{n}_{\mathrm{BDP}} / \mathrm{n}_{\text {amine, }}$, leveled off at the molar ratio BDP: amine equal to $4: 1 \mathrm{in} \mathrm{pH} \mathrm{3.75,} \mathrm{which} \mathrm{is}$ close to $\mathrm{pH}$ of BDP aqueous solution at the same concentration without amine (fig. 2, insert). The results are typical for a weak base titrated by a weak acid, although xymedon is a weak base and meglumine is medium-strength base $[24,25]$.

According to the dependence of microspecies distributions (\%) on $\mathrm{pH}$ (fig. 3) calculated using Chemicalize program, the main BDP ionic form at $\mathrm{pH} 3.75$ corresponds to two-charged ion and minor BDP ionic form is a single-charged ion. 
The interaction between BDP and amines can be characterized as one-stage proton transfer reactions from each BDP phosphate group.

\section{The study of proton transfer reaction of BDP with xymedon}

The acid-base interaction of BDP with amines was studied by UVand ${ }^{31} \mathrm{P}-\mathrm{NMR}$ spectra. BDP phosphate groups have absorption in the range of 240-270 $\mathrm{nm}$ [32]. The carbonyl chromophore band ( $\mathrm{n}-\pi^{*}$ and $\pi-\pi^{*}$ transitions) of xymedon was characterized by intense absorption in the region of $299 \mathrm{~nm}$, while the amino alcohol meglumine does not appear in this UV spectrum region. Therefore, it is possible to study BDP interaction with xymedon using a 299-nm band, while the interaction with meglumine can be controlled by phosphate group absorption only.
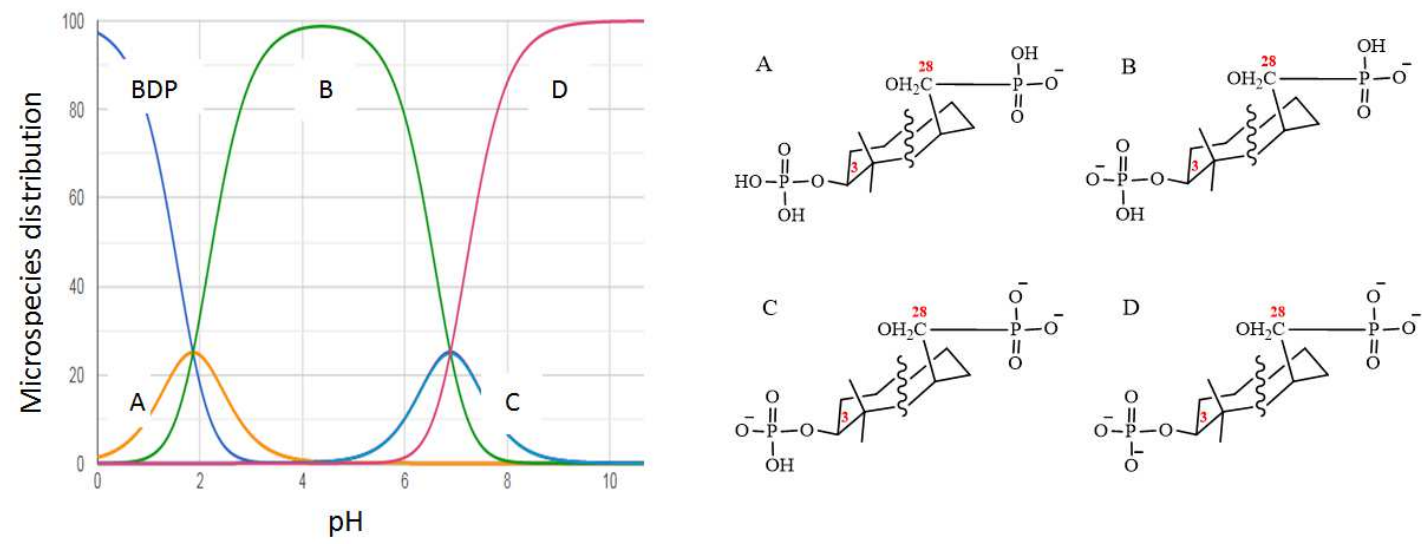

Fig. 3: The dependence of BDP microspecies distributions (\%) on pH calculated using Chemicalize program

The fully protonated xymedon form was characterized using xymedon hydrochloride salt as a control sample synthesized from ethylurea and acetylacetone in the presence of hydrochloric acid [20]. UV-spectrum of xymedon hydrochloride shows the absorption band with wavelength $\lambda_{\max }=308.8 \mathrm{~nm}$ in contrast to $\lambda_{\max }=299.0 \mathrm{~nm}$ for xymedon.

We studied the interaction of BDP with xymedon in aqueous solution in the conditions corresponded to potentiometric titration when xymedon concentration was the same $\left(5.9 \cdot 10^{-5} \mathrm{M}\right)$, and the ionic strength in the system was provided by $5.9 \cdot 10^{-4} \mathrm{M}$ lithium perchlorate.

The participation of xymedon in the proton transfer reaction with BDP in aqueous solutions was confirmed by bathochromic shift of the carbonyl chromophore band from $299.1 \mathrm{~nm}$ to $304.2 \mathrm{~nm}$, and a hyperchromic effect manifested in an increased molar absorption coefficient $\varepsilon$ from 8508 to $10441 \mathrm{l} \cdot \mathrm{mol}^{-1} \cdot \mathrm{cm}^{-1}$ (fig. $4 \mathrm{a}$, table 1 ).
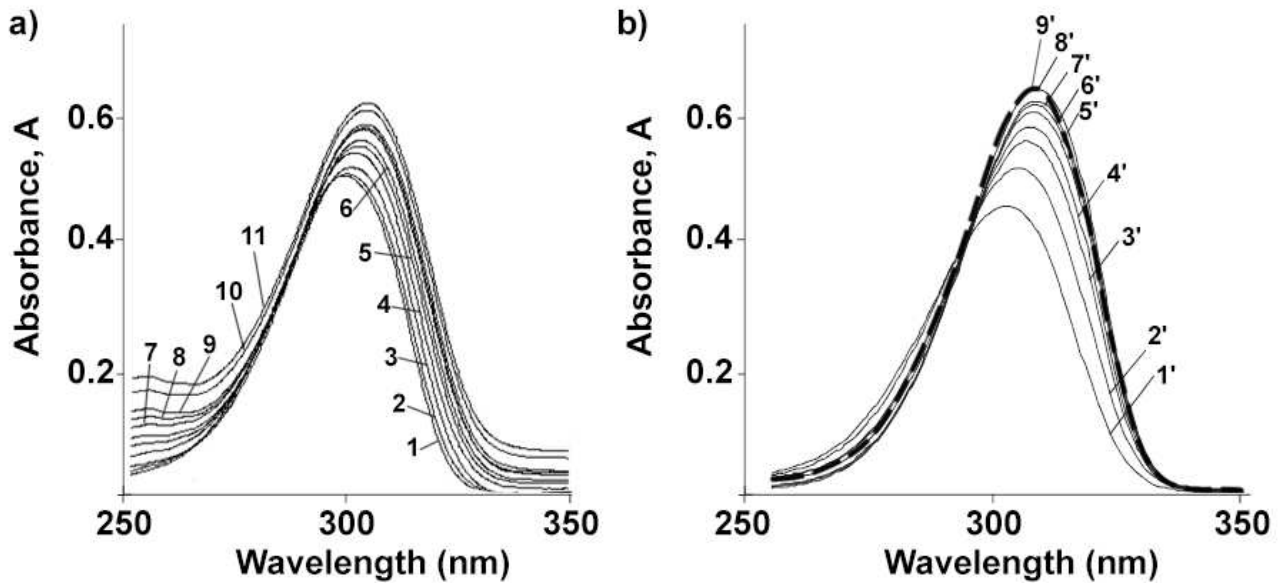

Fig. 4: UV absorption spectra of $5.9 \cdot 10^{-5} \mathrm{M}$ aqueous solution of xymedon and its protonated form obtained: a) in mixture with BDP; $\mathrm{C}_{\mathrm{Licl}}=$ $5.9 \cdot 10^{-4} \mathrm{M}$; b) in acetate-phosphate-borate buffer solution and in phytic acid (thick dashed line)

Spectra of xymedon and BDP mixtures were compared with those of xymedon salts obtained in aqueous acid solutions. The conditional molar extinction coefficient $\varepsilon$ of xymedon hydrochloride (standard sample) was equal to $10788 \mathrm{l} \cdot \mathrm{mol}^{-1} \cdot \mathrm{cm}^{-1}$, and the absorption band at $\lambda_{\max }$ equal to $309 \mathrm{~nm}$ practically coincided with the spectral characteristics of xymedon at the same concentration in $0.1 \mathrm{M}$ hydrochloric acid solution.

We compared "xymedon-BDP" with "xymedon-phytic acid" aqueous systems to estimate the role of phosphate groups in the interaction.
Acid-base properties of organic phosphates-phosphoric acid metabolic derivatives, such as various phosphorylated inositols-Ins $\mathrm{P}_{\mathrm{x}}$ $(x=1-6)$ and phytic acid InsP $\mathrm{P}_{6}$, glucose phosphates, glycerol phosphates, are similar to BDP. The ionization of phosphate groups of inositol and proton transfer reaction proceeds like the processes in aqueous phosphoric acid solution. The $\mathrm{pK}_{\mathrm{a}}$ values of the separation of the first and second protons of these compounds, as well as for phosphoric acid, are $1.5 \pm 0.5$ and $6.7 \pm 0.5$, respectively [33]. Moreover, phytic acid forms different kinds of complexes with amines due to not only proton transfer, but also non-specific covalent binding [34]. 
Table 1: The UV spectral data of $5.9 \cdot 10^{-5} \mathrm{M}$ xymedon solutions in various aqueous media (betulin-3,28-diphosphate BDP or buffer solution)

\begin{tabular}{|c|c|c|c|c|c|}
\hline \multirow[t]{2}{*}{ № } & \multicolumn{2}{|l|}{ Conditions } & \multicolumn{3}{|c|}{ UV spectral data } \\
\hline & $\alpha=\mathbf{n}_{\text {BDP }} / \mathbf{n}_{\text {Xym }}$ & pH & $\lambda, \mathbf{n m}$ & $\mathbf{A}$ & $\varepsilon^{\prime}, \mathrm{L} \cdot \mathrm{mol}^{-1} \cdot \mathrm{cm}^{-1}$ \\
\hline 1 & 0 & 5.76 & 299.1 & 0.502 & 8508 \\
\hline 2 & 0.5 & 4.75 & 299.8 & 0.505 & 8559 \\
\hline 3 & 1.0 & 4.10 & 300.7 & 0.516 & 8746 \\
\hline 4 & 1.5 & 4.02 & 301.6 & 0.539 & 9136 \\
\hline 5 & 2.0 & 3.96 & 302.5 & 0.549 & 9305 \\
\hline 6 & 2.5 & 3.92 & 302.9 & 0.558 & 9458 \\
\hline 7 & 3.0 & 3.88 & 303.5 & 0.575 & 9746 \\
\hline 8 & 3.5 & 3.82 & 303.6 & 0.578 & 9797 \\
\hline 9 & 4.0 & 3.79 & 303.9 & 0.583 & 9881 \\
\hline 10 & 4.5 & 3.75 & 304.1 & 0.605 & 10254 \\
\hline \multirow[t]{6}{*}{11} & 5.0 & 3.72 & 304.2 & 0.616 & 10441 \\
\hline & Acetate-phosphate- & 12.86 & 299.7 & 0.467 & 7908 \\
\hline & borate buffer & 11.86 & 299.7 & 0.458 & 7759 \\
\hline & & 11.24 & 299.8 & 0.458 & 7754 \\
\hline & & 10.67 & 299.8 & 0.457 & 7733 \\
\hline & & 6.00 & 299.9 & 0.453 & 7685 \\
\hline $1^{\prime}$ & & 3.99 & 302.8 & 0.452 & 7667 \\
\hline $2^{\prime}$ & & 3.72 & 305.3 & 0.513 & 8686 \\
\hline $3^{\prime}$ & & 3.40 & 307.0 & 0.554 & 9391 \\
\hline $4^{\prime}$ & & 3.22 & 307.6 & 0.577 & 9777 \\
\hline $5^{\prime}$ & & 2.92 & 308.1 & 0.600 & 10173 \\
\hline $6^{\prime}$ & & 2.62 & 308.5 & 0.611 & 10357 \\
\hline $7^{\prime}$ & & 2.31 & 308.7 & 0.618 & 10469 \\
\hline $8^{\prime}$ & & 1.33 & 308.8 & 0.637 & 10788 \\
\hline $9^{\prime}$ & Phytic acid ${ }^{1}$ & - & 308.7 & 0.637 & 10575 \\
\hline
\end{tabular}

${ }^{1} \mathrm{CPA}_{\mathrm{PA}}=1.0 \cdot 10^{-5} \mathrm{M}$, molar ratio of PA: Xym $=1: 6 . \alpha=\mathrm{n}_{\mathrm{PA}} / \mathrm{n}_{\mathrm{Xym}}=0.17$

Previously we showed that BDP like phytic acid forms salt complexes with amines [35] by proton transfer reaction like phosphoric acid.

The spectrum of xymedon in phytic acid solution with a molar ratio of phytic acid: xymedon = 1: 6 was the same as xymedon hydrochloride spectrum (fig. $4 \mathrm{~b}$, table 1). It is significant that a conditional molar extinction coefficient $\varepsilon$ was close to $10600 \pm 200$ $\mathrm{l} \cdot \mathrm{mol}^{-1} \cdot \mathrm{cm}^{-1}$ in all acid solutions under study at various $\mathrm{pH}$ values (table 1) and it was different from xymedon in water.
The results can probably be explained by the formation of xymedon and BDP complexes, when xymedon is not fully protonated, in contrast to xymedon salts formed by strong acids.

The significant increase of $\varepsilon$ when $\mathrm{pH}$ decreases from $\mathrm{pH} 6.00$ to $\mathrm{pH}$ 3.75 (corresponding to the plateau on $\mathrm{pH}=\mathrm{f}(\alpha)$ curve, fig. 2), and practically linear symbatic dependence of $\varepsilon$ on BDP molar fraction $\alpha$ in the same $\mathrm{pH}$ region (fig. $5 \mathrm{a}, \mathrm{b}$ ) prove the proton transfer between BDP and Xym.
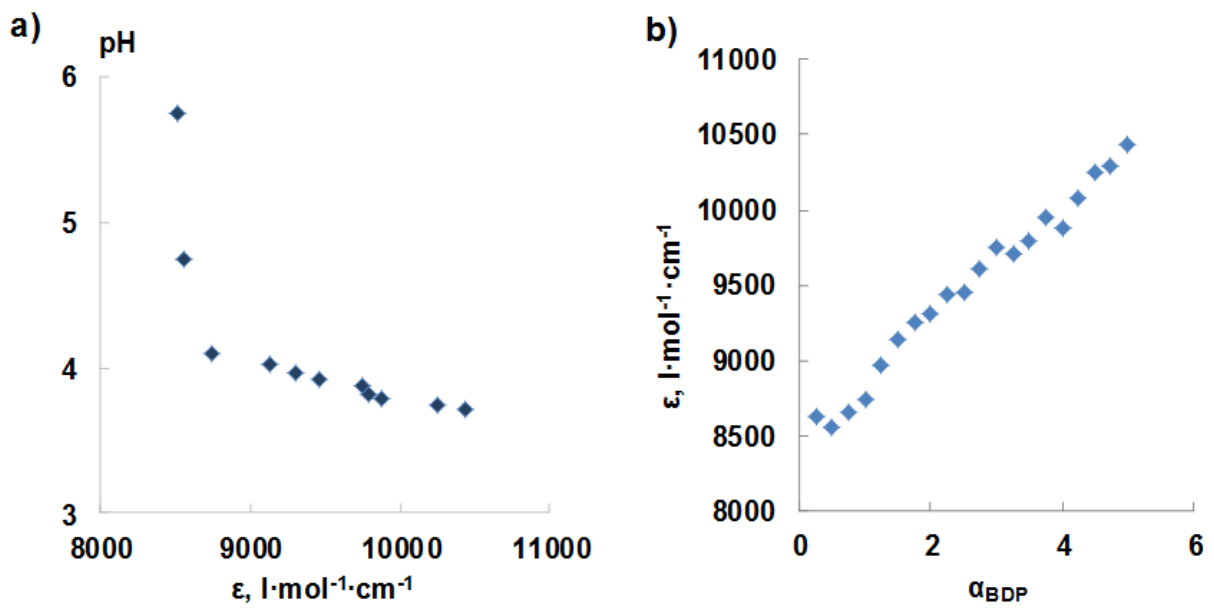

Fig. 5: a) The solution $\mathrm{pH}$ as a function of the molar extinction coefficient $\varepsilon, \mathrm{pH}=\mathrm{f}(\varepsilon)$; b) Dependence of the extinction coefficient $\varepsilon$ on $\alpha_{\mathrm{BDP}}$, $\varepsilon=\mathbf{f}\left(\alpha_{\mathrm{BDP}}\right)$

${ }^{13} \mathrm{C}$-and ${ }^{31} \mathrm{P}-\mathrm{NMR}$ spectral data of BDP-Xym mixture in $\mathrm{D}_{2} \mathrm{O}$ show the significant changes of spectra compared to the spectra of individual BDP and Xym (table 2, fig. 6). ${ }^{13} \mathrm{C}-\mathrm{NMR}$ spectra of xymedon hydrochloride and xymedon phytate were studied as well. Strong changes of chemical shifts of carbonyl carbon signals from $175 \mathrm{ppm}$ to $146-149$ ppm were observed in the spectra of all compounds under study (table 2). The signals of carbons designated C- 4 and C- 6 also changed. 


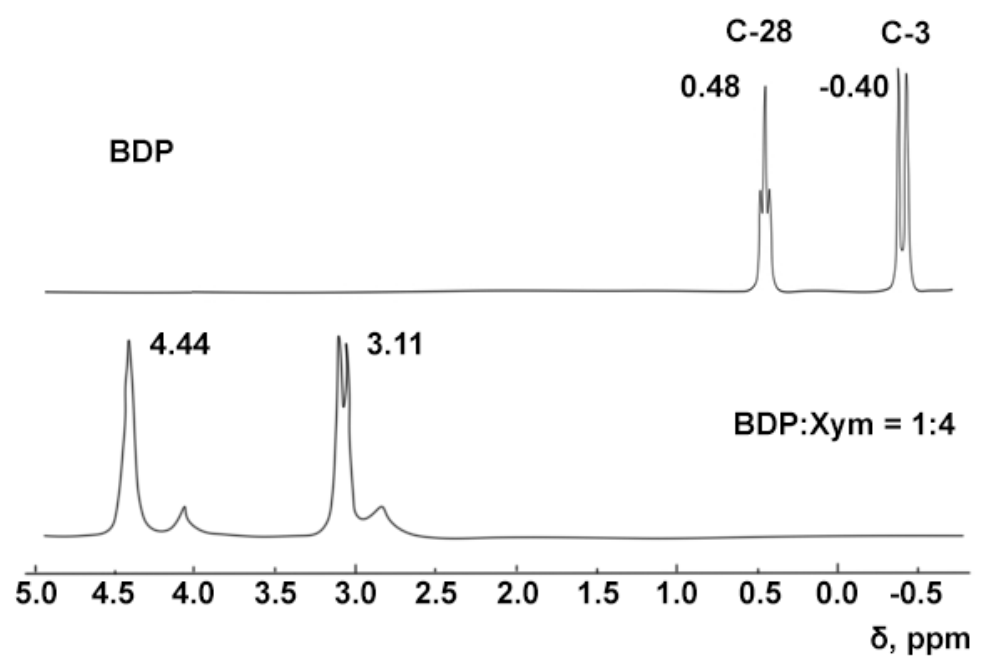

Fig. 6: ${ }^{31} \mathrm{P}-\mathrm{NMR}$ spectra of BDP (top) in DMSO-d $\mathrm{d}_{6}$ and BDP-Xym mixture (bottom) in $\mathrm{D}_{2} \mathrm{O}$. $\mathrm{PPh}_{3}$ is a standard

Table 2: ${ }^{13} \mathrm{C}-\mathrm{NMR}$ spectra of Xym, Xym-chloride, Xym-phytate $\left(\mathrm{D}_{2} \mathrm{O}\right)$ and Xym-BDP (DMSO-d $)$

\begin{tabular}{|c|c|c|c|c|c|c|c|c|}
\hline & & & $\overbrace{3}$ & $\mathrm{CH}_{2}$ & & & & \\
\hline Group & $-\mathrm{CH}_{3}$ (at C-6) & $-\mathrm{CH}_{3}$ (at C-4) & $\mathrm{N}-\mathrm{CH}_{2}(1)$ & $-\mathrm{CH}_{2}-\mathrm{OH}$ & $\begin{array}{l}H C= \\
(C-5)\end{array}$ & $C=N(C-4)$ & $\begin{array}{l}C= \\
(C-6)\end{array}$ & $\mathrm{C}=0(\mathrm{C}-2)$ \\
\hline \multicolumn{9}{|c|}{${ }^{13} \mathrm{C}$-NMR, $\delta$, ppm } \\
\hline Xym & 20.1 & 23.1 & 47.9 & 58.4 & 108.3 & 160.6 & 157.9 & 175.5 \\
\hline Xym-chloride & 19.4 & 21.7 & 49.4 & 57.8 & 108.3 & 172.1 & 168.5 & 149.0 \\
\hline Xym-phytate & 19.5 & 23.6 & 49.4 & 57.8 & 108.2 & 171.9 & 168.4 & 148.9 \\
\hline Xym-BDP & 18.0 & 21.3 & 48.8 & 57.6 & 106.5 & 169.7 & 166.8 & 146.4 \\
\hline
\end{tabular}

The chemical shift $\delta$ of phosphorus at C-3 atom of the pure BDP is equal to $-0.58 \mathrm{ppm}$ (doublet without decoupling from protons) and $\delta$ of phosphorus at $\mathrm{C}-28$ is equal to $+0.28 \mathrm{ppm}$. The chemical shifts of phosphorus atoms changed in BDP-Xym mixture spectrum (1:4) to+3.11 ppm at C-3 and to $+4.44 \mathrm{ppm}$ at $\mathrm{C}-28$. Two non-intensive and unresolved signals (close to the main signals, $\delta_{1}=2.7 \mathrm{ppm}, \delta_{2}=4.0 \mathrm{ppm}$ ) may describe the product of xymedon interaction with only one hydroxyl of BDP phosphate group.

Thus, taking into consideration the potentiometric titration data, UV and NMR spectra of reaction mixtures of BDP with xymedon, it is arguable that the interaction of BDP with xymedon proceeds with the formation of salt complexes and via a proton transfer reaction in the solution.
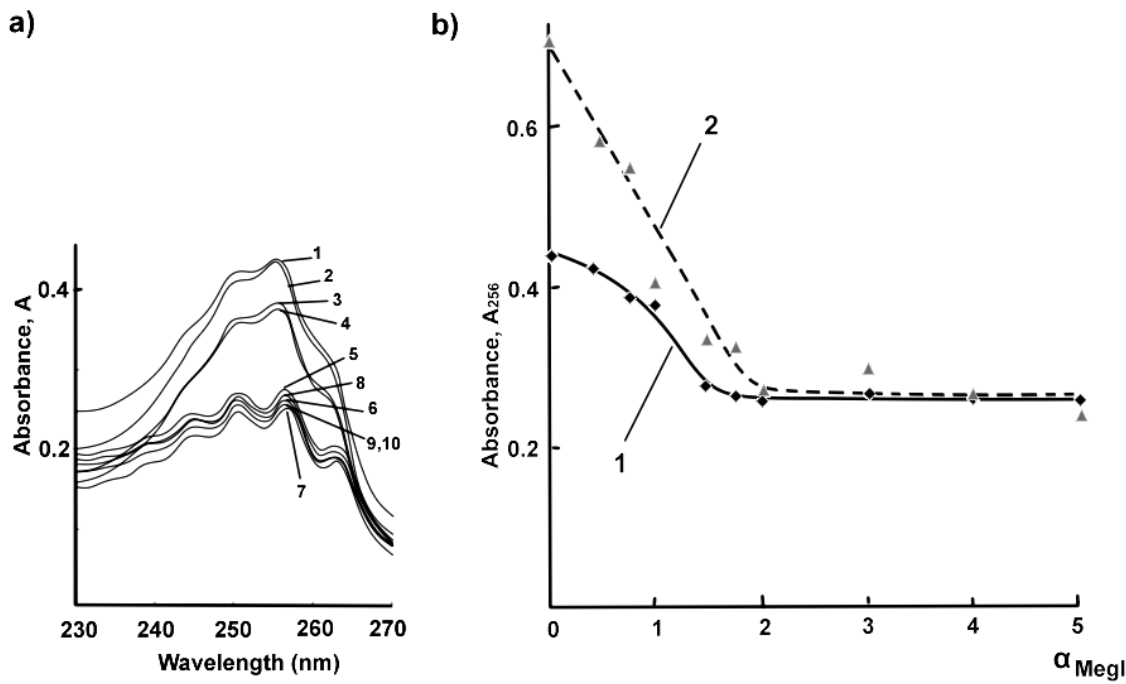

Fig. 7: The UV spectra in $5.1 \cdot 10^{-4} \mathrm{M}$ solutions of BDP in the presence of meglumine, $C_{\mathrm{Liclo4}}=1 \cdot 10^{-2} \mathrm{M}:$ a) $\mathrm{A}=\mathrm{f}(\lambda)$; b) the dependence of $A_{256}$ absorption on the molar ratio of meglumine to BDP, $A=f\left(\alpha_{\mathrm{Megl}}\right)$ in fresh solutions (1) and after $4 \mathrm{~d}(2), \alpha=\mathbf{n}_{\mathrm{Megl}} / \mathbf{n}_{\mathrm{BDP}}$ 


\section{The acid-base interaction of BDP with meglumine}

In the aqueous medium BDP UV-spectra were characterized by a band of the phosphate group ( $\mathrm{n} \rightarrow \mathrm{p}^{*}, \mathrm{p} \rightarrow \mathrm{p}^{*}$ transitions) at $\lambda_{\max }=256$ $\mathrm{nm}$. BDP phosphate groups under ionization can be considered as an amphoteric ion (B on fig. 3) both as an acid and a base conjugated to the acid. The molar extinction coefficient $\varepsilon$ of initial BDP in ethanol solution (curve 1 at fig. $7 \mathrm{a}$ ) is almost twice as much than $\varepsilon$ of BDP in $\mathrm{NaOH}$ aqueous solution that characterizes the ionized form, represented by base D presented in fig. 3. Therefore, absorption A values at $265 \mathrm{~nm}$ and, correspondingly, conditional molar extinction coefficient $\varepsilon$ can characterize BDP ionization and its interaction with Megl, which has no band in this region.

Fig. 7a shows the spectra of $5.0 \cdot 10^{-4} \mathrm{M}$ BDP and meglumine (Megl) mixtures at molar ratio $\alpha\left(\alpha=\mathrm{n}_{\text {Megl }} / \mathrm{n}_{\text {BDP }}\right)$ from 0 to 5 , when BDP concentration was $5.0 \cdot 10^{-4} \mathrm{M}$ and an ionic strength was supported by 1.10-2 $\mathrm{M} \mathrm{LiClO}_{4}$. Fig. 7 and table 3 data show $\mathrm{A}_{256}$ decrease while the molar ratio $\alpha$ increases.
It should be noted that the absorption of BDP phosphate groups changed with time during $4 \mathrm{~d}$ in aqueous solution without meglumine. Fig. $6 \mathrm{~b}$ ( 1 and 2 curves) shows the molar extinction coefficient $\varepsilon$ and the absorption increase approximately half as much. It may be explained by the increase with time of the BDP ionic A fraction having higher $\varepsilon$ values than $\varepsilon$ values of ionic B form in initial BDP solution.

After adding meglumine at essential meglumine excess $(\alpha \geq 2)$, absorbance $(A)$ and $\varepsilon$ values were the same and did not practically depend on $\alpha$. The "plateau" both on the curve $A=f(\alpha)$ (fig. 7b) and on the curve $\mathrm{pH}=\mathrm{f}(\alpha)$ (fig. 2) appears in $\alpha \geq 2$ region and reflects the same BDP ionization in BDP-Megl mixture under the studied conditions.

It is possible that such BDP ionization has the nature of the salt complex formation similar to BDP salt complexation with trisamine [35]. The composition of the BDP-trisamine complex was proved using Job's method, and the conditional stability constant equal to $1130 \mathrm{~mol} \cdot \mathrm{l}^{-1}$ was calculated [35].

Table 3: UV-spectra data according to fig. 8 a,b

\begin{tabular}{|c|c|c|c|c|c|c|}
\hline \multirow{2}{*}{$\begin{array}{l}\text { No } \\
\text { curve }\end{array}$} & \multirow{2}{*}{$\begin{array}{l}\alpha= \\
\mathbf{n}_{\text {Megl }} / \mathbf{n}_{\text {BDP }}\end{array}$} & \multirow{2}{*}{$\begin{array}{l}\mathrm{C}_{\mathrm{Megl}}, \\
\cdot \mathbf{1 0}^{4} \mathrm{M}\end{array}$} & \multicolumn{2}{|l|}{$\mathbf{A}$} & \multicolumn{2}{|c|}{$\varepsilon, \mathbf{l} \cdot \mathrm{mol}^{-1} \cdot \mathrm{cm}^{-1}$} \\
\hline & & & $\mathrm{A}_{0}$ & $\mathrm{~A}, \tau=4 \mathrm{~d}$ & $\varepsilon_{0}$ & $\varepsilon, \tau=4 \mathrm{~d}$ \\
\hline 1 & 0.00 & 0.00 & 0.437 & 0.709 & 874 & 1418 \\
\hline 2 & 0.50 & 2.50 & 0.435 & 0.580 & 870 & 1160 \\
\hline 3 & 0.75 & 3.75 & 0.384 & 0.546 & 768 & 1092 \\
\hline 4 & 1.00 & 5.00 & 0.376 & 0.401 & 752 & 802 \\
\hline 5 & 1.50 & 7.50 & 0.273 & 0.333 & 546 & 666 \\
\hline 6 & 1.75 & 8.75 & 0.262 & 0.327 & 524 & 654 \\
\hline 7 & 2.00 & 10.00 & 0.251 & 0.263 & 502 & 526 \\
\hline 8 & 3.00 & 15.00 & 0.268 & 0.295 & 536 & 590 \\
\hline 9 & 4.00 & 20.00 & 0.258 & 0.263 & 516 & 526 \\
\hline 10 & 5.00 & 25.00 & 0.258 & 0.236 & 516 & 472 \\
\hline
\end{tabular}

Note: $\varepsilon$ of BDP solutions $\left(1 \cdot \mathrm{mol}^{-1 \cdot} \mathrm{cm}^{-1}\right)$ : in $0.02 \mathrm{M}$ ethanol $\mathrm{H}_{2} \mathrm{SO}_{4}$ solution is 663 ; in $4 \cdot 10^{-3} \mathrm{M}$ aqueous $\mathrm{NaOH}$ solution is 418 ; in $95 \%$ ethanol-water (1:1) medium with $\mathrm{LiClO}_{4}$ is 761 .

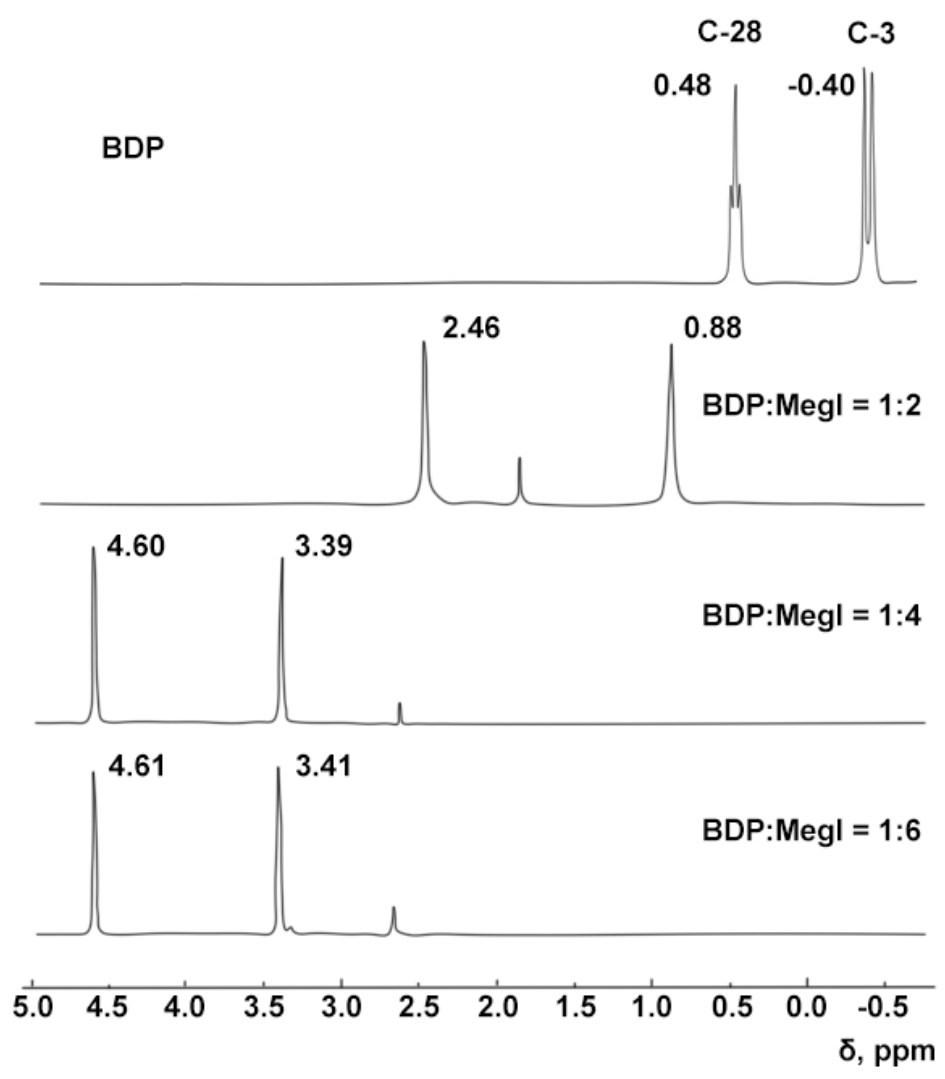

Fig. 8: ${ }^{31} \mathrm{P}-\mathrm{NMR}$ spectra of $\mathrm{BDP}-\mathrm{Megl}$ complexes in $\mathrm{D}_{2} \mathrm{O} . \mathrm{H}_{3} \mathrm{PO}_{4}$ is standard 
The interaction of BDP with meglumine in a solution was also studied using ${ }^{31} \mathrm{P}-\mathrm{NMR}$ spectra (fig. 8). The chemical shift of phosphorus at $\mathrm{C}-3$ atom of $\mathrm{BDP}(\delta=-0.58 \mathrm{ppm})$ changed to +0.88 ppm, and at C-28 atom ( $\delta=+0.28 \mathrm{ppm})-$ to $+2.46 \mathrm{ppm}$ in case of BDPmeglumine mixture $(1: 2)$. The chemical shifts depended on the BDP: meglumine ratio, and signals appeared in the weaker field with $\delta=+3.39$ ppm (at C-3) and $\delta=+4.60(\mathrm{C}-28)$ at molar BDP: meglumine ratio equal to $1: 4$ (fig. 8), similar to phosphorus signals of BDPxymedon salt complexes (fig. 6). The molar ratio of BDP: meglumine more than 1:4 did not change chemical shifts.

\section{BDP solubility and antioxidant activity of BDP salt complexes} with amines

The argument for strong intermolecular interactions of BDP with Megl, probably resulting in salt complexes formation in solution, is a sharp increase of BDP solubility in aqueous meglumine solutions (table 4). HPLC analysis showed that BDP solubility in water $\left(0.1 \mathrm{~g} \cdot \mathrm{l}^{-1}\right)$ significantly increased in the presence of meglumine, and the solubility of complex compounds did not depend on the initial BDP aging in storage (the transformation to BDP structural modification with lower solubility). The maximum BDP solubility in water (59 $\mathrm{g} \cdot \mathrm{l}^{-1}$ at $20{ }^{\circ} \mathrm{C}$ ) was achieved in the presence of meglumine at a molar ratio of components 1:4, BDP solubility being nearly 6 times greater than its solubility in the form of sodium salts. We studied the precipitates obtained by freeze-drying of BDP solutions with amines (at molar ratios of 1:1, 1:2, 1:4 and 1:6) as well. The ${ }^{31} \mathrm{P},{ }^{13} \mathrm{C}$-NMR and UV spectral data of aqueous solutions $\left(\mathrm{D}_{2} \mathrm{O}\right)$ of precipitates and initial components of model mixtures at same molar ratios were identical. The data suggest BDP dissolution in the meglumine medium to be largely due to hydrogen bonds, proton transfer interactions, and, ultimately, the interaction between the cationic and anionic parts of the complex components.

Table 4: Water solubility of BDP and its products at $20^{\circ} \mathrm{C}$ according to HPLC-analysis

\begin{tabular}{ll}
\hline Compound & $\mathbf{C}_{\text {BDP, }} \mathbf{g \cdot \mathbf { l } ^ { - \mathbf { 1 } }}$ \\
\hline BDP a & 0.15 \\
BDP b & 0.09 \\
Na-BDP a & 10.00 \\
Na-BDP b & 4.00 \\
BDP: Xym (molar ratio is 1:4) & 0.30 \\
BDP a: Megl (molar ratio is 1:4) & 59.00 \\
BDP b: Megl (molar ratio is 1:4) & 35.00 \\
\hline
\end{tabular}

afresh prepared, bafter storage during 3 mo.

The higher water-solubility of amorphous BDP-Megl salt complexes than crystalline Na-BDP can be explained by the stronger decrease of hydrophobic bonding between BDP dimer molecules by Megl due to hydrogen bonds. The effective antioxidant-regenerant xymedon, which has a high ability both to hydrogen bonding and to form stacking structures like pyrimidine, cannot significantly weaken the hydrophobic binding in the BDP dimer and, accordingly, improve its solubility. The poor watersoluble salt complex of xymedon with BDP is of interest as a dosage form of xymedon with an optimal dose, in contrast to its known dosage forms with very high dose (1500-2000 mg per day) due to its high solubility in water.

The antioxidant properties of aqueous solutions formed by BDP and amines: meglumine and xymedon, were studied by in vitro experiment on rat blood. The antioxidant activity of glutathione reductase and catalase, activity of glucose-6-phosphate dehydrogenase were studied using data as percentage of control (table 5). The effect of BDP-amine complexes on enzyme activity was compared to the effect of individual components.

Table 5: Biochemical indexes (catalase, glutathione reductase and glucose-6-phosphate dehydrogenase activities) of BDP-Megl and BDPXym mixtures in phosphate buffer (pH 6.86). Molar ratio of BDP: amine is 1:4

\begin{tabular}{|c|c|c|c|c|c|}
\hline \multirow[t]{2}{*}{ Compound } & \multirow[t]{2}{*}{ Dose of BDP, $\mu \mathrm{g} \cdot \mathrm{ml}^{-1}$} & \multirow[t]{2}{*}{ Dose of amine, $\mu \mathrm{g} \cdot \mathrm{ml}^{-1}$} & \multicolumn{3}{|c|}{ Index, $\%$ of control ${ }^{-1}$} \\
\hline & & & Catalase & GR & G6PD \\
\hline \multirow[t]{3}{*}{ BDP } & 2.0 & - & $159 \pm 14$ & $215 \pm 3$ & $132 \pm 3$ \\
\hline & 5.0 & - & $172 \pm 9$ & $179 \pm 3$ & $167 \pm 4$ \\
\hline & 10.0 & - & $153 \pm 7$ & $193 \pm 2$ & $137 \pm 2$ \\
\hline \multirow[t]{3}{*}{ Megl } & - & 2.6 & $114 \pm 4$ & $112 \pm 3$ & $113 \pm 2$ \\
\hline & - & 6.5 & $112 \pm 8$ & $143 \pm 3$ & $99 \pm 3$ \\
\hline & - & 13.0 & $91 \pm 3$ & $115 \pm 2$ & $110 \pm 1$ \\
\hline \multirow[t]{3}{*}{$\mathrm{BDP}+\mathrm{Megl}$} & 2.0 & 2.6 & $170 \pm 3$ & $239 \pm 3$ & $151 \pm 3$ \\
\hline & 5.0 & 6.5 & $237 \pm 5$ & $204 \pm 4$ & $188 \pm 5$ \\
\hline & 10.0 & 13.0 & $197 \pm 9$ & $225 \pm 2$ & $198 \pm 3$ \\
\hline \multirow[t]{3}{*}{ Xym } & - & 2.2 & $134 \pm 3$ & $133 \pm 2$ & $134 \pm 1$ \\
\hline & - & 5.6 & $152 \pm 5$ & $143 \pm 3$ & $99 \pm 4$ \\
\hline & - & 11.2 & $191 \pm 2$ & $185 \pm 5$ & $110 \pm 2$ \\
\hline \multirow[t]{3}{*}{$\mathrm{BDP}+\mathrm{Xym}$} & 2.0 & 2.2 & $195 \pm 5$ & $239 \pm 4$ & $151 \pm 3$ \\
\hline & 5.0 & 5.6 & $187 \pm 6$ & $204 \pm 8$ & $188 \pm 3$ \\
\hline & 10.0 & 11.2 & $157 \pm 8$ & $195 \pm 3$ & $159 \pm 5$ \\
\hline
\end{tabular}

${ }^{1}$ Number of replication of experiments was equal to 3. Biochemical indexes values are taken as $100 \%$; catalase-31.35 Ru/mg protein; glutathione reductase $-91.29 \mathrm{nmol}$ nicotinamide adenine dinucleotide phosphate (NADH)/min/mg protein, glucose-6-phosphate dehydrogenase- $52.37 \mathrm{nmol}$ $\mathrm{NADPH} / \mathrm{min} / \mathrm{mg}$ protein.

Table 5 data show that the BDP-amine complexes formation promoted the significant increase in catalytic activity of catalase, glutathione reductase and glucose-6-phosphate dehydrogenase compared to the control.

\section{CONCLUSION}

Thus, we firstly obtained the aqueous solution of betulin-3,28diphosphate as a potential antioxidant pharmaceutical active ingredient at BDP concentration up to $59 \mathrm{~g} \cdot \mathrm{l}^{-1}$ in the presence of meglumine. This fact is very important to prepare injectable and other hydrophilic formulations because a poorly water-soluble BDP loses its initial solubility during aging and storage by transition of structural modifications. On the other hand, the poor water-soluble salt complex of BDP with extremely water-soluble xymedon (up to $300 \mathrm{~g} \cdot \mathrm{l}^{-1}$ ) can be used as an effective antioxidantregenerant with an optimal dose. 
BDP interaction with amine (xymedon and meglumine) in an aqueous solution was shown to proceed via proton transfer due to relatively weak forces such as London forces, hydrogen bonding, electrostatic and hydrophobic interactions. In general, the formation of salt complexes of BDP with amines in solution determines BDP water solubility.

\section{AUTHORS CONTRIBUTIONS}

Nina Melnikova has made the contribution to design, analysis and conceptualizes the work. Darina Malygina, Dmitry Panteleev, Olga Vorobyova and Irina Klabukova have made the contribution to physicochemical experiments. Anna Solovyeva and Kseniya Belyaeva have made the contribution to biological activity assay. All authors read manually and approved the final manuscript.

\section{CONFLICTS OF INTERESTS}

The authors declare no conflict of interest.

\section{REFERENCES}

1. Kaur M, Yadav R. Pharmacognostic, ethnopharmacological, phytochemical and pharmacological profile of wild guava i.e. Careya arborea Roxb. Int J Curr Pharm Res 2017;9:1-7.

2. Perez J, Shen C-chang, Ragasa CY. Triterpenes from ceriops decandra (Griff.) W. Theob. AJPCR 2017;10:244-6.

3. Evanjaline M, Vr M. Determination of bioactive components of caralluma umbellata haw. (Apocynaceae) by gas chromatography and mass spectroscopy analysis. AJPCR 2018;11:194-9.

4. Meng Q, Zhou X, Liu L, Fu S. Research progress in the promissing natural product-betulin. Biomed J Sci Tech Res 2018;8:1-6.

5. Furtado NAJC, Pirson L, Edelberg H, Miranda LM, LoiraPastoriza C, Preat V, et al. Pentacyclic triterpene bioavailability: an overview of in vitro and in vivo studies. Molecules 2017;22:1-24

6. Yogeeswari P, Sriram D. Betulinic acid and its derivatives: a review on their biological properties. Curr Med Chem 2005;12:657-66.

7. So HM, Eom HJ, Lee D, Kim S, Kang KS, Lee IK, et al. Bioactivity evaluations of betulin identified from the bark of Betula platyphylla var. japonica for cancer therapy. Arch Pharm Res 2018;41:815-22.

8. Kim KJ, Lee Y, Hwang HG, Sung SH, Lee M, Son Y. Betulin suppresses osteoclast formation via down-regulating NFATc1. J Clin Med 2018;7:1-11.

9. Abyshev AZ, Abyshev RA, Nguyen VH, Morozova VA. Betulenol derivatives as potential anti-HIV agents. Med Academic J 2013;13:15-32.

10. Cao D, Zhao G, Yan W. Solubilities of betulin in fourteen organic solvents at different temperatures. J Chem Eng Data 2007;52:1366-8.

11. Dai L, Li D, Cheng J, Liu J, Deng LH, Wang LY. Water soluble multiarm-polyethylene glycol-betulinic acid prodrugs: design, synthesis, and in vivo effectiveness. Polym Chem 2014;5:5775-83.

12. Mikhailenko MA, Shakhtshneider TP, Eltsov IV, Kozlov AS, Kuznetsova SA, Karacharov AA, et al. Supramolecular architecture of betulin diacetate complexes with arabinogalactan from Larix sibirica. Carbohydr Polym 2016;138:1-7.

13. Drag Zalesinska M, Kulbacka J, Saczko J, Wysocka T, Zabel M, Surowiak $\mathrm{P}$, et al. Esters of betulin and betulinic acid with amino acids have improved water solubility and are selectively cytotoxic toward cancer cells. Bioorg Med Chem Lett 2009;19:4814-7.

14. Zhao H, Holmes SS, Baker GA, Challa S, Bose HS, Song Z. Ionic derivatives of betulinic acid as novel HIV-1 protease inhibitors. J Enzyme Inhibition Med Chem 2012;27:715-21.

15. Martin DE, Power MD. Pharmaceutical salts of 3-0-(3',3'dimethylsuccinyl) betulinic acid. Patent WO/2005/090380; 2005.
16. Bureeva S, Andia Pravdivy J, Symon A, Bichucher A, Moskaleva $\mathrm{V}$, Popenko V, et al. Selective inhibition of the interaction of $\mathrm{C} 1 \mathrm{q}$ with immunoglobulins and the classical pathway of complement activation by steroids and triterpenoids sulfates. Bioorg Med Chem 2007;15:3489-98.

17. Tubek B, Smuga D, Smuga M, Wawrzeńczyk C. Synthesis of 280-(1,2-Diacyl-SN-glycero-3-phospho)-betulin. Synthetic Communications 2012;42:3648-54.

18. Melnikova NB, Malygina DS, Klabukova IN, Belov DV, Vasin VA, Petrov PS, et al. Physico-chemical properties and in vitro biological activity experiments. Molecules 2018;23:E1175.

19. Krasutsky PA, Carlson RM, Karim MR. Triterpenes having antibacterial activity. U. S. Patent US 6,689,767 B2; 2004.

20. Krasutsky PA, Carlson RM, Karim MR. Triterpenes having human antifungal and antiyeast activity. U. S. Patent US 6,642,217 B2; 2003.

21. Amjad M, Carlson RM, Karim MR, Krasutsky PA. Inhibition of epstein-barr virus by the triterpenoid betulin diphosphate and uvaol. J Microbiol Biotechnol 2004;14:1086-8.

22. Chrobak E, Bebenek E, Kadela Tomanek M, Latocha M, Jelsch $\mathrm{Ch}$, Wenger E, et al. Betulin phosphonates; synthesis, structure, and cytotoxic activity. Molecules 2016;21:1123.

23. Vorobyova O, Deryabina O, Malygina D, Plotnikova N, Solovyeva A, Belyaeva K, et al. Betulin-3,28-diphosphate as a component of combination cytostatic drugs for the treatment of ehrlich ascites carcinoma in vitro and in vivo experiments. Sci Pharm 2018;86:17.

24. Basavaraj S, Sihorkar V, Shantha Kumar TR, Sundaramurthi P, Srinivas NR, Venkatesh P, et al. Bioavailability enhancement of poorly water soluble and weakly acidic new chemical entity with 2-hydroxy propyl-b-cyclodextrin: selection of meglumine, a polyhydroxy base, as a novel ternary component. Pharm Dev Technol 2006;11:443-51.

25. Mehramizi A, Alijani B, Pourfarzib M, Dorkoosh FA, Rafiee Tehrani M. Solid carriers for improved solubility of glipizide in osmotically controlled oral drug delivery system. Drug Dev Ind Pharm 2007;33:812-23.

26. Izmaylov SG, Parshikov VV. Ksimedon: nastoyashchee i budushchee. Nizhny Novgorod Med J 2002;3:81-7.

27. Kuznetsova SA, Skvortsova GP, Maliar IN, Skurydina ES, Veselova OF. Extraction of betulin from birch bark and study of its physico-chemical and pharmacological properties. Russ J Bioorganic Chem 2014;40:742-7.

28. Jouyban A. Handbook of solubility data for pharmaceuticals. 1st ed. New York: Taylor and Francis Group; 2010.

29. Packer L. Catalase in vitro. In: Methods in enzymology. Vol. CV. Cambridge: Academic Press: 1984.

30. Sibgatullina GV, Khartendinova LR, Gumerova EA, Akulov AN, Kostyukova YuA, Nikonorova NA, et al. Methods for determining the redox status of cultured plant cells. Kazan (Russia): Kazan (Privolzhsky) Federal University: 2011.

31. Kochetov GA. Practical guide to enzymology. 2nd ed. Severin SE. editor. Moscow: High School: 1980.

32. Ryzhova ES, Panteleev DA, Chudetskaya YV, Volkov AA, Melnikova NB, Gulenova MV, et al. Chemical properties and immunotropic activity of the products from reaction of $\mathrm{N}-(6-$ methyl-2,4-dioxo-1,2,3,4-tetrahydro-5H-pyrimidinesulfone)$\mathrm{N}^{\prime}$-isonicotinoylhydrazide with acids and bases in aqueous media. Pharm Chem J 2010;44:205-12.

33. Williams VR, Williams HB. Basic physical chemistry for the life sciences. 2nd ed. San Francisco: W. H. Freeman and Co. Ltd.; 1973.

34. De Stefano C, Giuffre O, Milea D, Rigano C, Sammartano S. Speciation of phytate ion in aqueous solution. Non covalent interactions with biogenic polyamines. Chem Spec Bioavailab 2002;15:29-36.

35. Melnikova NB, Malygina DS, Solovyeva ON, Zhiltsova OE, Vasin VA, Petrov PS, et al. Betulin-3,28-diphosphate salt complexes with amines and their antioxidant activity. Int J Pharm Pharm Sci 2018;10:87-95. 